Int.J. Hum. Soc. Dev. Res.

ISSN (P):2521-1439; ISSN (E):2523-4331

Volume 3, Number 2, 2019. 7-20

DOI:10.30546/2523-4331.2019.3.2.7

\title{
IMPACT OF THE PERCEPTION OF TOXIC LEADERSHIP OF HEALTHCARE PROFESSIONALS ON ORGANIZATIONAL COMMITMENT AND QUALITY OF WORK LIFE
}

\author{
Nuriye ÇELMEÇE \\ Near East Universty, Turkish Republic of Northern Cyprus
}

\author{
Abdullah IŞIKLAR \\ Bursa Technical Universty, Turkey
}

(C) The Author(s) 2019

\begin{abstract}
Performance of the human resources' affects the quality of outcome and services for any organization, particularly service organization. Previous studies explored large number of factors influence employee's job satisfaction and job performance. In this study we aimed to analyze the relationship of distributing factors (pay, HRMP, work environment, motivation, and promotion) with nurses' job satisfaction and job performance. Questionnaire with 5-Likert scale was distributed to randomly selected nurses (160) from the 15 different private healthcare institutions from Bangladesh. Hypotheses were tested by using statistical software (SPSS). Correlation and regression analysis showed a significant positive correlation between variables like pay structure, human resource management practice, work environment, motivation, and promotion with both job satisfaction and performance of the nurses. A strong positive correlation has been found between nurses' job satisfaction and job performance. Practical implication and future implication of the research direction have been discussed and recommended accordingly.
\end{abstract}

C2019.All rights reserved

\section{ARTICLE HISTORY}

Received: $18 / 01 / 2019$

Accepted: 09/7/2019

Published online: 03/10/2019

\section{KEYWORDS}

Healthcare services, nurses, job satisfaction, job performance, work environment 


\section{Introduction}

The leader as a person who guides others to act in line with a certain goal, inspires and influences them and make them to follow himself/herself voluntarily (Çelmeçe \& Işıklar, 2015; Koçel, 2014 ). Many leadership theories and approaches have been developed from past to present and characteristics, behaviors, situational attitude and behaviors of leaders have been taken into consideration when developing them. In the simplest sense, the aim of these approaches have been defining and developing the perfect leader and it was always considered that leaders will always accomplish positive results. Because when the word leader was mentioned, always "positive leaders" have came to mind and it was never considered that leaders would lead to negative results or harm the organization they lead and their followers with the decisions they make. It is observed in the investigated leadership theories in literature that there are leaders who are extremely oppressive, disordered and prone to excessive work and communication and these leaders negatively influence organizations and followers with their behaviors, attitude and decisions (Celep, 2014; Gedikoğlu, 2015; Güney, 2015; Yıldız, 2015). As a result of these researches many negative qualities have been blended and the resulting leadership concept is called "toxic leadership".

According to Lipman-Bluemen (2005), toxic leadership is a kind of poison that creates serious and influential pressure on the personality of the employees. Toxic leaders neglect welfare of employees (Schmidt, 2008), overwhelm and criticize the employees and make force them to submit with threats and authority (Lipman-Blumen, 2005) and only focus on their own interests and pay not attention to others (Schmidt, 2008) (Kırbaç, 2013). The management style in an organization directly influence expansion of negative effects such as hopelessness, anger, low morale, poor 
communication (Eğinli \& Bitirim, 2008); burnout, distrust (Bektaş \& Erkal, 2015); low productivity of employees and negative cost-benefit relationship in organizations, increased rate of absenteeism, reduction of the quality of work life (Schmidt, 2008) and increased organizational cynicism.

Toxic leaders are malevolent, maladjusted, malcontent and harmful. They succeed by hiding their inefficacy, deceiving the people around them and sweeping over their rivals. Furthermore, toxic leaders are mocking, trickster, immoral, unreliable, hypocrite, greedy, they place their own interests before benefit of their followers, they don't recognize their deficiencies and therefore cannot renew themselves, they cannot see their own faults due to their arrogance, they cannot make important decisions due their cowardice and they don't care about the effects of their attitude and behaviors on others (Başar, Sığrı \& Basım, 2016 Daniel \& Metcalf, 2015; Dinh, Lord, Gardner, Meuser, Liden, \& Hu, 2016).

Along with personality traits of leaders, their type of leadership in business life is also an important factor affecting numerous behavioral and psychological circumstances such as organizational commitment of employees, their intention to leave the work or stay, quality of their work life, performance and job satisfaction level. Reyhanoğlu and Akın (2016) have found out in their research that toxic leaders create a negative environment in an organization and negatively influence organizational outcomes such as job satisfaction, intention to leave the work and organizational commitment.

In cases where organizational commitment is high, it can be said that performance, quality of work life and organizational productivity of employees increase but absenteeism and employee turnover decrease (Erdem, 2007). The employees who feel committed to their institution 
believe in institution's objectives and values, carry out the orders and voluntarily perform what is expected from them. Moreover, these employees try harder than it is expected from them so that their institution would achieve its objectives and they are decisive to stay with the institution. Employees with high organizational commitment are internally motivated.

Since organizational commitment refers to strength of the commitment felt by the employees for their organization, it is believed that the feeling of organizational commitment positively affects organizational performance and organizational productivity which is the determinant of employee productivity and in this context, it is suggested that organizational commitment decreases negative results like the rate of being late to work, absenteeism and leaving work, positively affects products and services and increases the quality of work life (Meyer and Allen, 1997; Çelmeçe, Işıklar, Macar and Kaya; 2017).

In every business a powerful leader is needed who would efficiently direct human resources in line with the objectives of the business. It is possible to talk about this need in health institutions. Another factor which increases organizational commitment, job satisfaction and indirectly, the quality of work life of healthcare professionals is leaders who would continuously improve their knowledge of management and timely respond to changing conditions of competition with new methods (Aryee, Walumbwa, Zhou, \& Hartnell; Lazarus, 2009; Naidoo, Hewitt, \& Bussin, 2019; Uno \& Zakariasen, 2010).

In this study, it is aimed to determine the impact of toxic leadership perception of healthcare professionals on their organizational commitment 
and quality of work life. In line with this purpose, answers will be sought for the questions below;

1- Is there a relationship between health professionals' perception of toxic leadership and their organizational commitment and quality of work life?

2- Does healthcare professionals' perception of toxic leadership have an impact on their organizational commitment and quality of their work life?

\section{Method}

In order to determine the impact of toxic leadership perception of healthcare professionals on their organizational commitment and quality of their work life, relational screening model is used in the research. The universe of the study is composed of healthcare professionals working in Tokat Gazlosmanpaşa University Hospital Sample of the study consists 246 healthcare professionals, 160 of them (65\%) of whom are female and 86 of them $(35 \%)$ are male determined by random sampling method.

\section{Measurement Tools:}

\section{Toxic Leadership Scale:}

In order to measure the perception level of employees regarding Toxic Leadership, the scale developed by Çelebi et al. (2015) basing on the scale of "Development and Validation of the Toxic Leadership Scale" developed by Schmidt (2008) is used the scale has four sub-dimensions named unappreciativeness (11 items), self-seeking (9 items), selfishness (5 items) and negative state of mind (5 items). In the reliability analysis of the scale Cronbach's Alpha coefficient are found as 0.938 for 
unappreciativeness, 0.936 for self-seeking, 0.807 for selfishness and 0.890 for negative state of mind.

\section{Organizational Commitment Scale:}

"Organizational Commitment Scale" developed by Meyer and Allen (1991) and adapted to Turkish by Wasti (2000) is used. This five point Likert type scale was scored between "strongly disagree" (1) and "strongly agree" (5) and consists of 18 items in three dimensions (affective commitment, normative commitment and continuance commitment). At the end of the analyses conducted by Wasti (2000) to test the validity of the scale, it is revealed that the Turkish version of the scale validates 3dimensional structure of original scale and factor load values of scale items vary between 20 and 72. In addition, reliability coefficient is calculated as $0.78,0.75$ and 0.58 for affective commitment, normative commitment and continuance commitment respectively.

\section{Quality of Work Life Scale:}

The Quality of Work Life Scale was developed in 2001 by Sirgy, Efraty, Siegel and Lee. The scale consists of 16 items related to the satisfaction of 16 needs. All the items of the scale measure the quality of work life in the workplace. The first three items of the scale $(1,2,3)$ measure the satisfaction of the need of health and safety. Items 4,5 and 6 measure the satisfaction of family and economic needs. Items 7 and 8 measure the satisfaction of social needs. Items 9 and 10 measure the level of satisfaction of the need of respect. Items 11 and 12 measure the extent to which self-realization needs are satisfied. Items 13 and 14 measure the extent to which information needs are satisfied. Items 13 and 14 measure the extent to which information needs are satisfied. Questions 15 and 16 are intended to measure the satisfaction level of aesthetic needs. Sirgy, Efraty, Siegel and Lee (2001) have made a confirmatory factor analysis to test the 
construct validity of the authentic scale and revealed that 16 items come from seven factors and these seven factors come from a single factor. The Cronbach Alpha reliability coefficient of the Quality of Work Life Scale is calculated as 0.78 .

\section{Findings}

Findings regarding the correlations between healthcare professionals' perception of toxic leadership and their organizational commitment levels and quality of work life are given in Table 1.

Table 1: Correlations between healthcare professionals' perception of toxic leadership and their organizational commitment levels and quality of work life.

\begin{tabular}{lllllll}
\hline & $\mathbf{1}$ & $\mathbf{2}$ & $\mathbf{3}$ & $\mathbf{4}$ & $\mathbf{5}$ & $\mathbf{6}$ \\
\hline 1. Unappreciativeness & - & & & & & \\
2. Self-seeking & $.65^{* *}$ & - & & & \\
3. Selfishness & $.56^{* *}$ & $.67 * *$ & - & & \\
4. Negative State of & $.62^{* *}$ & $.70^{* *}$ & $.70^{* *}$ & - & \\
Mind & & & & & \\
5. Organizational & - & - & - & - & - \\
Commitment & $.27^{* *}$ & $.29 * *$ & $.23 * *$ & $.21 * *$ & \\
6. Quality of Work Life & - & - & - & - & \\
& $.36^{* *}$ & $.31 * *$ & $.37 * *$ & $.31 * *$ & $.33 * *$ & - \\
& & & & & \\
\hline$* \mathbf{p}<.05 * * \mathbf{p}<.01$ & & & & &
\end{tabular}

The results of the correlation analysis made to determine the existence and direction of the relationship between the sun-dimensions of toxic leadership and organizational commitment and quality of work life are shown in Table 1. 
As seen in Table 1,weak and negative relationships have been found between organizational commitment and unappreciativeness $(r=-0,27$ $\mathrm{p}<0,001)$, self-seeking $(\mathrm{r}=-0,29 \mathrm{p}<0,001)$ and fairly weak and negative relationships have been found with selfishness $(r=-0,23 \mathrm{p}<0,001)$ and negative state of mind $(r=-0,210 \mathrm{p}<0,001)$ all of which are sub dimensions of toxic leadership. According to this result, it can be said that if perception level of participants regarding unappreciativeness, self-seeking, selfishness and negative state of mind of their leaders/managers increase, their organizational commitment will decrease.

Negative and weak relationships are found between the quality of work life and sub-dimensions of toxic leadership; with unappreciativeness ( $\mathrm{r}=-0,36$ $\mathrm{p}<0,001)$, self-seeking $(\mathrm{r}=-0,31 \mathrm{p}<0,001)$, selfishness $(\mathrm{r}=-0,37 \mathrm{p}<0,001)$ and negative state of mind $(\mathrm{r}=-0,31 \mathrm{p}<0,001)$. According to these results, it can be said that the quality of work life decreases as the level of perception of participants regarding unappreciativeness, self-seeking, selfishness and negative state of mind of their managers increases.

Multiple regression analysis is made to test the impact of sub-dimensions of toxic leadership on organizational commitment and quality of work life and these analyses are given in Table 2 and Table 3.

Table 2: The impact of sub-dimensions of toxic leadership on organizational commitment of healthcare professionals

\begin{tabular}{|c|c|c|c|c|c|c|c|}
\hline Independent Variables & $\mathbf{B}$ & SS & $\boldsymbol{\beta}$ & $\mathbf{p}$ & $\mathbf{R 2}$ & $\mathbf{F}$ & $\overline{\mathbf{P}}$ \\
\hline Constant & 4.387 & 0.287 & & & \multirow{5}{*}{0.148} & \multirow{5}{*}{7.412} & \multirow{5}{*}{0.000} \\
\hline Unappreciativeness & -0.440 & 0.142 & -0.377 & 0.008 & & & \\
\hline Self-seeking & -0.007 & 0.157 & -0.007 & 0.973 & & & \\
\hline Selfishness & -0.148 & 0.008 & -0.142 & 0.137 & & & \\
\hline Negative State of Mind & -0.289 & 0.119 & 0.239 & 0.019 & & & \\
\hline
\end{tabular}


It can be said that $15 \%$ of organizational commitment in Table 2 is explained by sub-dimensions of toxic leadership; unappreciativeness, selfseeking, selfishness and negative state of mind. According to the result of Table 2, it is seen that unappreciativeness dimension of toxic leadership $(\mathrm{B}=-0,440 ; \mathrm{p}=0,008)$ is in a reverse interaction with organizational commitment. In this case, it can be said that organizational commitment decreases as unappreciativeness increases. Once again according to Table 2, it is seen that the negative state of mind sub-dimension of toxic leadership $(\mathrm{B}=-0,289 ; \mathrm{p}=0,019)$ negatively interacts with organizational commitment. According to this result, it can be said that organizational commitment decreases as the negative mental state increases. On the other hand, it is seen that sub-dimensions of self-seeking $(p=0,973)$ and selfishness $(p=0,137)$ of toxic leadership do not have an impact on organizational commitment.

Table 3: The impact of sub-dimensions of toxic leadership on quality of life of healthcare professionals

\begin{tabular}{|c|c|c|c|c|c|c|c|}
\hline Independent Variables & B & SS & $\boldsymbol{\beta}$ & $\mathbf{p}$ & $\mathbf{R 2}$ & $\mathbf{F}$ & $\mathbf{p}$ \\
\hline Constant & 1.122 & 0.291 & & & \multirow{5}{*}{0.281} & \multirow{5}{*}{11.59} & \multirow{5}{*}{0.000} \\
\hline Unappreciativeness & $\overline{-} \overline{431}$ & 0.133 & -0.397 & 0.001 & & & \\
\hline Self-seeking & $\begin{array}{c}- \\
0.312\end{array}$ & 0.148 & -0.252 & 0.012 & & & \\
\hline Selfishness & $\begin{array}{c}- \\
0.301 \\
\end{array}$ & 0.121 & -0.244 & 0.002 & & & \\
\hline Negative State of Mind & $\begin{array}{c}- \\
0.171\end{array}$ & 0.111 & -0.122 & 0.000 & & & \\
\hline
\end{tabular}

It can be said that $28 \%$ of quality of work life in Table 3 is explained by sub-dimensions of toxic leadership; unappreciativeness, self-seeking, selfishness and negative state of mind. According to Table 3, it is seen that sub-dimensions of toxic leadership, namely unappreciativeness $(B=-0,431$; $p=0,001)$, self-seeking $(B=-0,312 ; p=0,012)$, selfishness $(B=-0,301 ; p=$ 
$0,002)$ and negative state of mind $(B=-0,171 ; p=0,000)$ have a negative impact of the quality of work life.

\section{Discussion and Conclusion}

Toxic leadership has negative effects on workers such as loss of confidence, inefficiency, interruption of communication, increase in organizational commitment and dismissal, reduction in quality of work life (Steele, 2011). These negative impacts may affect the employees' organizational commitment, quality of work life and tendency to quit. In this context, this research has examined the relationship between toxic leadership perceptions and organizational commitment and job quality of health professionals working in Tokat Gaziosman Pasha University Hospital.

Within the scope of this study, which was carried out with the participation of 246 health workers, important findings about the relationships between the variables were revealed. A negative relationship was found between toxic leadership and its sub-dimensions and organizational commitment and quality of work life. According to this result, it may be asserted that as the perception level of participants regarding unappreciative, self-seeking, selfish, and negative state of mind about their leaders/managers increase, their organizational commitment and quality of work life will decrease.

According to the results of the research, it can be said that $15 \%$ of organizational commitment are explained by sub-dimensions of toxic leadership which are unappreciativeness, self-seeking, selfishness and negative state of mind. It is seen that unappreciativeness dimension of toxic leadership has a reverse interaction with organizational commitment. In this case, it can be said that organizational commitment decreases as 
unappreciativeness increases. It is also seen that negative state of mind subdimension of toxic leadership has a negative interaction with organizational commitment. According to this result, it can be said that organizational commitment decreases as the negative mental state increases. On the other hand, it is seen that self-seeking and selfishness sub-dimensions of toxic leadership do not have an impact on organizational commitment.

According to the results of the research it can be said that $28 \%$ of the quality of work life is explained by sub-dimensions of toxic leadership; unappreciativeness, self-seeking, selfishness and negative state of mind. It is seen that sub-dimensions of toxic leadership, unappreciativeness, selfseeking, selfishness and negative state of mind have a negative impact on the quality of business life.

In Dvorakova and Fedorova's (2014) research in which they revealed the relationship between toxic leadership, toxic workplaces and quality of business life, a negative correlation was found between toxic leadership and toxic work places and quality of work life. Mehta and Maheshwari (2013) found a negative correlation between toxic leadership behaviors and job satisfaction and organizational commitment in their researches to determine toxic leadership behaviors and to investigate the relationships between toxic leadership behaviors, job satisfaction and organizational commitment. These findings supported our study.

In the study conducted by Ballı and Çakıcı (2016) with 604 hotel employees, it was found that employees' commitment to the organization decreased as toxic leadership increased. These results supported our research. Again, the research conducted by Yalçınsoy and Işık (2018) in the textile sector, and Weaver and Yancey (2010), there was a negative 
correlation between toxic leadership and organizational commitment of employees. These results also supported our research.

As a consequence, it is important for health managers to be aware of the toxic leadership behaviors and organizational commitment of health workers and their quality of work in terms of developing strategies towards eliminating toxic behaviors in order to prevent all potential negativities. In this context, the increase and spread of the exhibition level of these toxic behaviors is a point that requires attention. It is necessary to identify the variables that increase these behaviors and attitudes, and to work on understanding and solving the behaviors and attitudes exhibited by health managers. As the level of toxic behavior of managers in health institutions increases, the organizational commitment and the quality of work life of employees will decrease. This situation shows that health managers should be more careful about toxic leadership and necessary precautions should be taken to minimize the perceptions of toxic leadership in their institutions.

\section{Disclosure statement}

No potential conflict of interest was reported by the authors.

\section{Contact Information}

E-mail: pskapo@hotmail.com 


\section{References and notes:}

Aryee, S., Walumbwa, F. O., Zhou, Q., \& Hartnell, C. A. (2012). Transformational leadership, innovative behavior, and task performance: Test of mediation and moderation processes. Human Performance, 25(1), 1-25. https://doi.org/10.1080/08959285.2011.631648.

Başar, U., Sığrı, Ü., \& Basım, N. (2016). Obscure leadership in the workplace. Job and Human Magazine, 3(2), 65-76. https://doi: 10.18394/iid.61037.

Bektaş, M., \& Erkal, P. (2015). Toxicity behaviors in organizations: a study on validity and reliability of emotional toxic experiences scale. Research Journal of Business

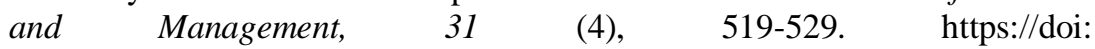
10.17261/Pressacademia.2015414060.

Celep, C. (2014). Leadership behavior of training manager. Ankara: Nobel Publishing.

Çelebi, N., Güner, H, \& Yıldız, V. (2015). Development of toxic leadership scale. Bartın University, Faculty of Education Journal, 4 (1), 249 - 268. https://doi: 10.14686/BUEFAD.2015111056.

Çelmeçe, N., \& Işıklar, A. (2015). Perceived relationship between leadership and quality of work life by healthcare professionals. Journal of Academic and Social Researches, 3 (20), 202-216.

Çelmeçe, N., Işıklar, A., Dikmen,T. and Moslen, M. (2017). An examination of the relationship among obesity, quality of life and job performance in health personnel. Quest Journals Journal of Research in Humanities and Social Science, 5 (4), 58-64.

Çetinkaya, H. (2017). The relationship between toxic (poisonous) behaviors of school executives and burnout level of teachers. Postgraduate Thesis, Pamukkale University, Institute of Education Sciences, Denizli.

Daniel, T. A., \& Metcalf, G. S. (2015). Crossing the line: An examination of toxic leadership in the US Army. The Leadership Quarterly, 32, 118-227.

Demirel, N. (2015). The relationship between toxic leadership behaviors of school principals and organizational cynicism attitude of teachers (Case of Gaziantep Sehitkamil County). Postgraduate thesis, Kahramanmaras Sutcu İmam University, Gaziantep.

Dinh, J. E., Lord, R. G., Gardner, W. L., Meuser, J. D., Liden, R. C., \& Hu, J. (2016). Leadership theory and research in the new millennium: Current theoretical trends and changing perspectives. The Leadership Quarterly, 25(1), 36-62. https://psycnet.apa.org/doi/10.1016/j.leaqua.2013.11.005.

Eğinli, A. T., \& Bitirim, S. (2008). The barrier in front of corporate success: poisonous (toxic) communication. Selcuk University, Academic Journal of Faculty of Communication, 5 (3), 124-140.

Erdem, R. (2007). The relationship between types of organizational culture and organizational commitment: A study on the hospitals in city center of Elazig province. Eskisehir Osmangazi University IIIBF Magazine, 2 (2), 63 - 79.

Gedikoglu, T. (2015). Leadership and School Management. Ankara: Anı Publishing.

Güney, S. (2015). Leadership. Ankara: Nobel Publishing.

Hartley, D. (2009) Education policy, distributed leadership and socio-cultural theory. $\begin{array}{llllll}\text { Educational } & \text { Review, } & 61 & \text { (2), } & 139 & -\end{array}$ https://doi.org/10.1080/00131910902844721.

Kırbaç, M. (2013). Toxic leadership in educational organizations. Postgraduate thesis, Inonu University, Malatya.

Koçel, T., (2014). Business Management: Management and Organization in Organizations. Behavior, Classic-Modern-Contemporary and Current Approaches, İstanbul: Beta Publishing. 
Lazarus, A. (2009). Professional and career issues in administrative medicine. Journal of Healthcare Leadership, 1, 1-5. https://doi.org/10.2147/JHL.S7846.

Lipman-Blumen, J. (2005). Toxic leadership: When grand illusions masquerade as noble visions. Leader to Leader, 36, 29-36. https://doi.org/10.1002/lt1.125.

Mehta, S., \& Maheshwari, G. (2013). Consequence of toxic leadership on employee job satisfaction and organizational commitment. Contemporary Management Researches, 8 (2), 1-23.

Meyer, J., \& Allen, N. (1997). Commitment in the Workplace: Theory, Research and Application. Sage Publications. http://dx.doi.org/10.4135/9781452231556.

Murphy, L. (2005). Transformational leadership: a graded chain reaction. J Nurs Manag, 13 (2), 128-36. https://doi.org/10.1111/j.1365-2934.2005.00458.x.

Naidoo, S., Hewitt, M., \& Bussin, M. (2019). A leadership model validation: Dimensions influential to innovation. South African Journal of Business Management, 50 (1), 1-11. http:// doi: 10.4102/sajbm.v50i1.1294.

Reyhanoğlu, M., \& Akın, Ö. (2016). Does toxic leadership negatively affect organizational health? Human and Social Sciences Researches Journal, 5 (3), 442-459.

Schmidt, A. A. (2008). Development and validation of the toxic leadership scale. Postgraduate thesis, University of Maryland, USA.

Uno, H., \& Zakaiasen, K. (2010). Public health leadership education in North America. Journal of Healthcare Leadership, 2, 11-15. http:// doi: 10.2147/JHL.S972.

Yalçınsoy, A., \& Işık, M. (2018). A Study on the Relationship of Toxic Leadership with Organizational Commitment and Intention to Leave Work. Gaziantep University Journal of Social Sciences, 17 (3), 1016-1025. https://doi.org/10.21547/jss.373835.

Y1ldı, S. M. (2015). Leader-member interaction, relationship between mobbing and occupational burnout in the workplace. Ankara: Detay Publication. 